\title{
Special Event Logistics Geopolitical Event Bangkok
}

\author{
Hermann Gruenwald \\ Burapha University International College, Bangsaen, Thailand \\ GruenwaldH@yahoo.com
}

\begin{abstract}
Special event logistics covers a broad area from concerts, trade fairs, to public gatherings and beyond. This qualitative research is looking at special event logistics from a technical logistics management standpoint. The paper focuses on the logistics issues of the geopolitical events of the so called Shut down of Bangkok in 2014. The paper does not address the political issues surrounding the events and takes a neutral position only focusing on the technical logistics elements of the special event. Geopolitical special events are different as they involve thousands of volunteers at various levels of engagement over a more or less undetermined period of time with very fluid dynamics of the event. The emotions of the volunteers and participants are running high as it involves political and ideological viewpoints and therefore provides a high tension high pressure environment with a great level of uncertainty and risk. Supply chain risk management (SCRM) takes on a new meaning in the context of special events. Security is a major issue which goes beyond normal SCRM and business continuity planning. There needs to be access and crowd control as well as VIP and critical infrastructure protection. The logistics issues that need to be addressed include: site selection and preparation down to site dissolution, various sorts and types of assets and supplies from numerous and often daily varying sources need to be mobilized and demobilized. Infrastructure has to be provided and in some cases created including public utilities such as electricity, water, sewer, phone, fax, internet and mobile telephones, cable, wireless networks, satellite up and down links, to ATM machines which have to be brought to the site. Food and beverages (F\&B) services range from drinking water to feeding thousands to special diets for vegetarians, Buddhist monks and Muslim participants. Storage on-site and off-site involves coldsupply chain (CSC) as well as perishable items and bulk items ranging from less than a truck load (LTL) to large bulk shipments. Audio visual (AV) services and multi-media needs to be covered both on a close circuit (CCTV) network for the site as well as national and international news and media coverage. There are also the demand planning and transportation issue, goods and people have to be transported to and from and in between often multiple venues which adds to the complexity.
\end{abstract}

Keywords: Special Event Logistics, Logistics Management, Geopolitical Events, Volunteer Logistics, Meeting Planning, Event Logistics

\section{Introduction}

Modern logistics deals with the integration of the entire supply chain from farm or factory to the end-user or consumer. Special event logistics on the other side is closer to the origins of logistics, looking not only at transportation and storage but every logistical aspect of the special event. Logistics is all about getting the right stuff to the right people at the right time in the right amount. Geographical political event logistics involves the logistics of events with a political undertone. This starts with small gatherings to protests and beyond. Special event logistics for geopolitical events includes a number of special issues depending on the magnitude of the event. The magnitude of the event can easily be measured by the number of participants which ranges from a meeting of a few to gatherings of thousands. Besides the number of participants the other factor is the duration of the event, which may be from a few hours to a few days or several months. Naturally the duration has a great impact on the amount of support required. The setting or so called venue of the event is another contributing factor to the complexity of the event, which may take place in-doors in an office, hotel, convention center or other place which may already has the facilities and support infrastructure required to support the event. A conference hotel naturally is specialized in "special event logistics", it provides the basic needs of food and shelter in form of conference rooms, with audio visual (AV) equipment seating arrangements, air conditioning, and rest room facilities in addition can provide food and beverage (F\&B) services from water to coffee breaks to lunch and dinner. The hotel can also provide accommodations for events that last longer than a day or have participants from far away. An outdoor event is a totally different mater and the focus of this research. Also a single event for a morning is different than having multiple events in parallel or in sequence. Another complexity is the issue of single of multiple locations. Events which take place at only 
one venue are easier to handle than multiple venues or events that move to various venues over time. Multiple venues consume not only more resources but are also exponentially more difficult to coordinate and support from a management standpoint.

This in addition to complexity and duplication brings in the issue of transportation of people material and equipment between the various sites. Besides these complexity issues the event can also be seen in the framework of fulfilling the basic needs of the participants according to Maslow' Hierarchy of needs (Maslow, 1970). First there are the physiological needs that include food and shelter from the elements along with the sanitary requirements and the means of modern creature comfort as far as possible. The shelter issue may vary depending on the season and location as weather can be a major factor with an outdoor event and rain can quickly disperse the event. The safety issue is a major issue as safety concerns may keep people from participating. Safety includes both physical safety as well as protection of property and health. The event also satisfies the need of love and belonging, as friends and family join in the site and it is a gathering of politically likeminded. Even the need for esteem through respect for others and by others can be gained at these events, down to self-actualization in problem solving and creativity. The logistics of these events make all this possible and cover the full spectrum of satisfying the hierarch of needs. The way event is perceived is dependent on the individual perception of the participants which includes the sociological aspects and group dynamics dealt with in the sociology literature (Bell, 1969).This paper does not discuss the social dynamics and political issues surrounding the event, nor the legal and law enforcement issues, it strictly deals with the technical logistics issues and makes no value judgments.

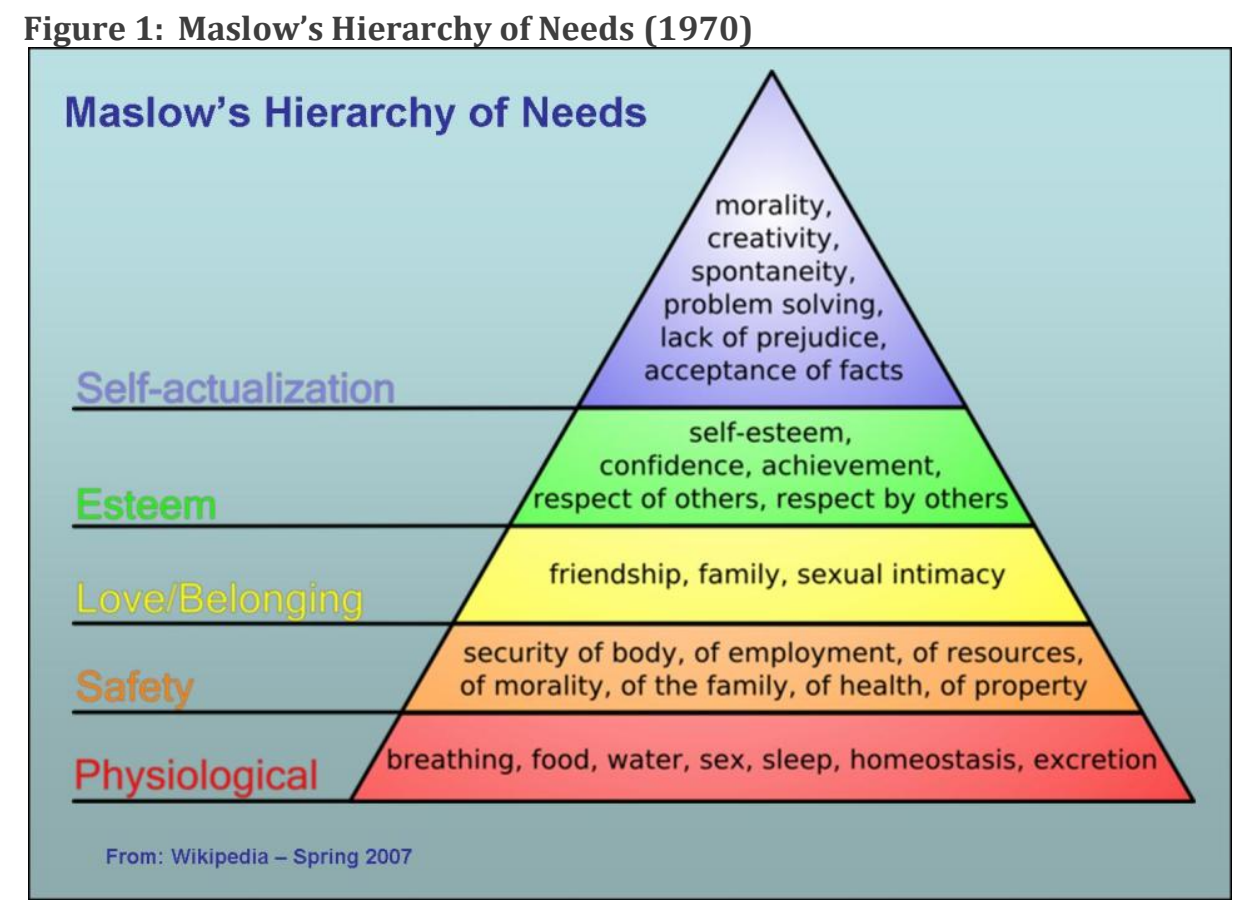

\section{Literature Review}

The literature review looks at various main bodies of literature: logistics literature, hotel \& restaurant management literature, sociology, political science literature and history. The political science literature deals with the dynamics behind the political events. There has been extensive coverage of the Bangkok Shutdown in the Thai and international press, which served as secondary sources for this paper. But the literature review looks at the theory behind geopolitical events in general and not in the particular geographic context. The literature also goes back several years to deal with the events leading up to the event. As pointed our earlier this paper does not deal with the political issue but focuses on the logistic aspect of the event. From a logistics standpoint the political literature was found less helpful as it deals less with the technical than with the philosophical issues. This rich body of political literature reaches back not only decades but hundreds and even thousands of years. Very quickly a point is reached where one crosses over from politics to history (Chenoweth and Orion, 2013). As quoted too many times history repeats itself and people should learn from history, but naturally there are various interests involved 
which prevents us to learn from history or provide us with a tendency to repeat history consciously or unconsciously. Historically we can look at western history or into Asian history. Gatherings and historical events of the Egyptians, Greeks and Romans down to modern times in France, England and Germany can be used as historic benchmark. The bible itself is a historical description of special events. The movement of the tribe of Israel through the dessert over two thousand years ago, under the leadership of Moses required a large amount of logistics coordination. Whenever two or more people are gathered the sociological aspects come in play and the event is perceived differently by different people. The hotel and restaurant management literature deals with the aspects of food and beverages and lodging. Within the hospitality industry literature is a division which deals with event logistics in the hotel such as meetings and conferences down to special events such as weddings and conventions. Meeting planners provide another rich body of literature which leads into tourism (Boehme, 1999). Convention planning is another specialty body of literature. A totally different special event planning literature is those of trade shows and road shows (Armstrong, 2001). Road shows have a further specialty which is outdoor concerts. Outdoor events are quite different from indoor events as the infrastructure normally is none existing and has to be created for the special event (Nichols, 2003). Outdoor concerts are probably the closest parallel study one can find. Outdoor concerts usually take place over the weekend also need to provide accommodations for the audience who often camp out in front of the stage or in close proximity, and require adequate sanitary installations and food and beverage service along with other items provided by vendors from event merchandizing down to apparel, rain cover and daily necessities. Special event logistics in the literature are also often simply referred to as event logistics, event services. The special event logistics literature covers many of these events and is a cross over discipline between the logistics and hospitality industry. Many times the companies which provide the logistics for the hospitality industry also branch out into special events logistics. As third party logistics companies (3PL) they can provide a one-stop shopping place for everything and take care of all phases of the event from planning, organizing and designing the experience to executing the event and providing all the services from bringing the utilities to the site, the shelter, AV and security. T here is a big difference between planning a trade show or even a racing event compared to handling the logistics for a political event (Robbe, 2000). Expositions and Trade Shows the political event has many volunteers and stake holders involved at various levels. The literature review provided us with a template for special events to analyze this geopolitical event and develop a more specific theory for geopolitical events and especially for events a given time and place context.

\section{Figure 2: Bodies of Literature related to Special Event Logistics Logistics}

\section{Special Events}

\section{Meeting Planners}

\section{Hotel \& Restaurant}

$$
\text { Sociology }
$$

\section{Political}

\section{Methodology}

\section{History}

This qualitative study interviewed participants and stakeholders of geopolitical events in Thailand, namely in Bangkok from December of 2013 till end of March 2014. The methodology followed Grounded Theory by Glaser \& Strauss (1967) and had open-ended questions with in-depth probing, to obtain the perception of the participants of the various events. As with any qualitative study it focuses on the perception of the individuals. The paper does not quote individuals or identifies individuals to protect their identity. The findings also do not include magnitudes of any kind when it comes to quantities, as the numbers cannot be quoted. The study looks at the phenomenon at hand and the general solutions to the special event logistics problems. The qualitative study followed the time line of the event and was created while the event was still ongoing, with changing dynamics and the final outcomes of the event were uncertain. This is a snap shot in time looking at the logistics efforts of the event and not on the political aspects of the event, strictly a technical study for lessons learned and establishing industry best practices when it comes to geopolitical events, event management and special event logistics and supply chain management (SCM) and logistics in general under the special context.

\section{Results}

The results of this study are summarized in the following topic areas: 
Timing: The Bangkok Shutdown was scheduled for Monday January $13^{\text {th }}, 2014$, with various warm-up events before that in December of 2013. The end of the event was not in sight when this paper was written, which was almost three months into the event after the election on February 2, 2014 and after the event moved to Lumpini Park on Monday March 3, 2014. People to varies levels were on site 24/7. With the levels increasing during day time and on weekends and during more intense activities, with both local as well as participants from other parts of the country. The event took place during the Thai winter months, which to great deal determined the weather for the event. As the event would extend into the Thai New Year - Songkran holiday season dynamics would set in.

Weather: The weather gods are of critical importance at any outdoor event. The event started January $13^{\text {th }}$ which was in the Thai winter. The winter of 2013/2014 was particularly cold considering the average temperature in Thailand. Naturally it was not freezing cold, but cold enough for participants to wear heavier clothing and an occasional blanket to protect especially infants from the cold. These items had to be partially be provided by the organizers, as well as hand fans and electrical fans, and air conditioning units in special locations. The event was blessed with a climate that provided creature comfort as it was not too hot or too cold and no major rainstorms interrupted the event. The raining seasons would have different challenges including potential flooding of the sites. So in January there was no need to keep the water away from the participants from the top or the bottom, even so plastic cover and roofing for the venues were provided.

Table 1: Temperature and Precipitation during the Event

\begin{tabular}{lllll}
\hline Weather & \multicolumn{2}{l}{ January $\mathbf{2 0 1 4}$} & \multicolumn{2}{l}{ February 2014 } \\
\hline & Actual & Normal & Actual & Normal \\
High Temperature & $30 \mathrm{C}$ & $32 \mathrm{C}$ & $33 \mathrm{C}$ & $33 \mathrm{C}$ \\
Low Temperature & $20 \mathrm{C}$ & $20 \mathrm{C}$ & $24 \mathrm{C}$ & $22 \mathrm{C}$ \\
Average Temperature & $25 \mathrm{C}$ & $26 \mathrm{C}$ & $28 \mathrm{C}$ & $27 \mathrm{C}$ \\
Precipitation & $0 \mathrm{~mm}$ & $\mathrm{~N} / \mathrm{A}$ & $8 \mathrm{~mm}$ & $\mathrm{~N} / \mathrm{A}$ \\
\hline
\end{tabular}

Venue: The selection of the venue is the critical element of any special event, location, location, location, the same as in real-estate. In the case of the shut-down the venue has to provide both visibility as well as political impact. There is the decision of a single venue or multiple venues. And there may be a main venue and secondary venues. To impact the traffic, visibility and political importance, Bangkok was chosen as the main venue for the shutdown, which leads to the title of the operation Bangkok Shut-Down. As Thailand is a centralized country with Bangkok being the hearth of Thailand and the capital, Bangkok was the obvious choice for the venue. There have been other sites with activities throughout the country at various times but these are not the focus of this research paper.

Table 2: Venues

\begin{tabular}{|c|c|c|c|c|c|c|}
\hline Venue & AKAS & Overpass & Intersection & Bus & BTS & MRT \\
\hline Lumpini Park & Silom & yes & & $\mathrm{x}$ & $\mathrm{x}$ & $\mathrm{X}$ \\
\hline Victory Monument & & & Major & $\mathrm{x}$ & $\mathrm{x}$ & \\
\hline Government & & & & $\mathrm{x}$ & & \\
\hline Complex & & & & & & \\
\hline Asoke & & & & $\mathrm{x}$ & $\mathrm{x}$ & \\
\hline Pathumwan & MBK & & & $\mathrm{x}$ & $\mathrm{x}$ & \\
\hline Lat Phrao & & yes & & $\mathrm{x}$ & & $\mathrm{X}$ \\
\hline Ratchaprasong & Central World & & & $\mathrm{x}$ & indirect & \\
\hline
\end{tabular}

Food and Beverage (F\&B): Food and beverages are of vital importance role for special events especially if they take place over several days, weeks or months. The people have to be fed and food plays a particularly important role in Thai culture. One has to say nobody has been starving at these events. There has been plenty of food for every taste; there has been a northern kitchen for those who like more spicy northern food, southern kitchen for those from the south and special food for Muslim, down to hallal meat. To cook for large crowds is a special challenge, and has been handled through several kitchens rather than through one large centralized kitchen. There were food shipments from as far away as from the south of Thailand close to the Malaysian border hundreds of thousands of eggs were shipped from there. Tons of vegetables, rice and meat especially chicken, were donated or provided at discounted 
prices. Cooking for those masses also takes on a particular task and requires a large amount of people. Not only the cooking is an issue but also the dish washing of the cooking utensils and some of the dishes. Even so most of the food was served in Styrofoam and paper which was folded into food containers by volunteers. There was a large variety of homemade dishes which were provided by volunteer donors, down to specialty dishes and desserts and ice cream and Thai style cold and hot drinks including three-inone Nescafe and fresh brewed espresso and mocha. Food and snacks were available 24/7. There also was sufficient bottled drinking water available and optional ice cubes for those who liked it cold.

Transportation: There is a large requirement for transportation which was more or less centrally coordinated. Some of the transportation needs are provided as part of the services of the vendor, donor or provider under the Inco terms. These may include the transportation of the various articles by the vendors such as merchandise that is for sale by independent vendors. While other items such as vegetables and various food supplies need pick-up to be arranged by the organizers to get the items from the donors to the site. Another huge transportation issue is that of people movement from one venue to another. There are shuttle services available via so called song taoe - pickup trucks with seating arrangements in the rear. There are also regular buses used not only for local transport but to get participants from various parts of Thailand to the site. There also needs to be coordination of air transportation for VIPs who come in by various means of air transport who need to be picked up from the various airports Suvanabumi and Don Muang and be escorted to the site or their accommodations. As part of the warm-up marches and rally there is movement of an assortment of vehicles, ranging from motorbikes, tuck-tucks, private cars, to buses and large trucks. This requires a transportation management system and also the refueling of the vehicles is a challenge as any single gas station would not be able to handle the entire fleet. Fleet management becomes an important component of the logistics puzzle. Public transportation to and from Bangkok and to the sites played an important role. Most venues were directly accessible by sky train and in some cases also by MRT like in the case of Silom, Lumpini Park, Asok, Victory Monument, and Ladprao, which made it convenient for Bangkonians to join the events. The sites were more difficult to reach by car and major intersections were blocked through the sites and even detours ended up in traffic jams. Parking at the sites usually took place in terms of roadside parking with parts of the road being closed for parking or the use of near-by commercial parking structures.

Table 3: Transportation

\begin{tabular}{lllll}
\hline Transportation & National & & \multicolumn{2}{c}{ Regional/Local } \\
& Cargo & Passenger & Cargo & Passenger \\
\hline Air-Transport & $\mathrm{X}$ & $\mathrm{X}$ & & limited \\
Private Car & $\mathrm{X}$ & $\mathrm{X}$ & $\mathrm{X}$ & $\mathrm{X}$ \\
Truck & $\mathrm{X}$ & $\mathrm{X}$ & $\mathrm{X}$ & $\mathrm{X}$ \\
Van & $\mathrm{X}$ & $\mathrm{X}$ & $\mathrm{X}$ & $\mathrm{X}$ \\
Bus & $\mathrm{X}$ & $\mathrm{X}$ & $\mathrm{X}$ & $\mathrm{X}$ \\
Sky train/MRT/BRT & & & & $\mathrm{X}$ \\
\hline
\end{tabular}

Security and Safety: Security is a major issue at any special logistics event and goes beyond that of normal supply chain risk management. The security issues to be addressed are both the security of the participants and items inside the venue and on the way to and from the venue. Who has access to the venue with what in their pockets. Access gates have been used which consisted of normal side walk metal barricades. On occasions hand held metal detectors were used and handbags and backpacks were searched. Crowd control is an issue at any special event, to regulate the flow of people and access to the venue and certain areas. The prevention of a stampede is a concern wherever crowds accumulate, especially around the stages and in the temporary housing areas (Tarlow, 2002). Also parking close to the venue sites needs parking assistance and control. In Thailand the access with motorbikes is an issue that needs to be addressed, while bicycles usually are free to access the sites. Another important security issue is the security of VIPs who come to the site as participants, audience, performer or speaker. Political events add another dimension of security to the event. The fire hazard as these events are another major issue usually the fire department and fire marshal has to be coordinated with (Health and Safety Executive, 1999). In the USA this is a major concern of public safety and there are special regulations on the type of material that can be used at the venues without creating a fire hazard. In addition to fire prevention there is the concern of response of the fire department in case of a fire, which mean access to and from the site has to be provided as well as water that can be used to extinguish a potential fire, along 
with sufficient fire department equipment and manpower. Water may be in water tanks and open containers for smaller fires as well as access to fire hydrants which are on the site.

Accommodations: The event was frequented both by local Bankonians and participants from out of town. While local participants went home at night or maybe occasionally joined friends to a sleep over at the venue. Out of town participants had to be accommodated at the site. The events are taken place in open air, and therefore need to literally be covered to prevent both sunshine and rain to directly impact the participants. Large scale tent structures with a curved roof were the shelter of choice with the sides being open and only poles would provide structural support of the roof along with diagonal bracing, the columns were stabilized by plastic counter weights in form of tanks filled with water. Individuals still wanted their private space which was provided under the tents structures in form of small tents or moscito net enclosures, which were either provided or brought to the site by the participants. In the case of Lumpini Park there was a tent city created, actually it was more like a serious of small villages some had very scenic sites including lake front property. The tent cities provided also all necessary creator comforts including toilet and shower as well as laundry facilties.

Personal Hygiene: For personal hygiene rest room facilities were provided either in form of plastid port toilets as well as shower facilities for both men and women. In addition there were mobile toilets and screened areas for showers. The toilets were emptied using waste removal trucks which pumped out the toilets. There were no raised toilets on elevated platforms used, these are common in Thailand and allow gravity to empty the toilets in tanks on the ground. In addition to water for showering water was provided to do daily laundry which could be hung on laundry lines which will strung in designated areas as in the case of Lumpini Park or along the sleeping accommodations and tent cities, bushes also were welcomed areas for hanging or lying cloth.

Animals: Pets provided another logistics challenge as some people brought their pet to the site. Most of these pets were small dogs which could easily be carried in the hand bag. Occasionally the sites were also visited by neighborhood dogs and cats. Naturally the food provided on the site also attracted mice and rats and other rodents which had to be taken care off in a catch and release program. In the case of Lumpini Park participants could also enjoy wild animals which at the site like bird's squirrels and fish for which pet food could be purchased at the site. Creative business people also provided dog grooming onsite in a booth in Lumpini Park, which was well received by some of the participants.

Waste Management: Waste management is a major issue at these events especially if they take part over extended periods of time. Human waste has to be removed along with various types of waste ranging from food leftovers, used dishes and utensils as well as recycling paper and plastic material. The human waste was removed by the city using pump trucks. The garbage was collected in green, yellow and transparent plastic garbage cans as well as plastic bags. The green city garbage trucks came on a regular basis. The plastic mostly came from plastic water bottles and other beverage containers. Styrofoam food containers created light weight but large volume of waste to be removed. The recycling was an easy task as plastic was seen as a valuable resource that easily could be cashed in on.

Healthcare: There was extensive healthcare coverage on the site which went way beyond that found at similar events in Europe or the USA. Besides ambulances and emergency medical services (EMS), there were on-site "field hospitals" which had medicals doctors, interns, nurses, aids and pharmacists working there. There was even a makeshift ward in Lumpini Park where people could take a rest if they suffered from heat exposure or had some other medical condition which required them to lay down, naturally there were stretchers, wheel chairs and all types of first aid equipment and medical check-up which went beyond the triage. Many medical doctors, medical students and nurses volunteered on site. Hospitals dispatched ambulances to be on standby in case of need of medical transports. The site also provided a full functional pharmacy which suspended drugs for free to anybody seeking medical assistance.

Religious Services: Buddhist monks were invited to speak and live at the site and provided a spiritual component to the event. There were monks from various temples at the site, who stayed for varied periods of time. In the spirit of okomene catholic priests as well as Muslim muezzins also participated and for believers of the Muslim faith prayer tents were erected for both male and females. Special accommodations and food had been provided for Buddhist monks as well as other clergy in the way of Thai tradition and respect for the monks who have separate seating arrangements in public places. 
Table 4: Healthcare

\begin{tabular}{lllll}
\hline Healthcare & $\begin{array}{l}\text { On-Site } \\
\text { Out- } \\
\text { Patients }\end{array}$ & $\begin{array}{l}\text { In- } \\
\text { Patients }\end{array}$ & $\begin{array}{l}\text { Off-Site } \\
\text { Out- } \\
\text { Patients }\end{array}$ & $\begin{array}{l}\text { In- } \\
\text { Patients }\end{array}$ \\
\hline Fist Aid & $\mathrm{X}$ & & $\mathrm{X}$ & $\mathrm{X}$ \\
Emergency Medical Services (EMS) & $\mathrm{X}$ & $\mathrm{X}$ & $\mathrm{X}$ \\
Triage & $\mathrm{X}$ & $\mathrm{X}$ & $\mathrm{X}$ & $\mathrm{X}$ \\
Optometry & $\mathrm{X}$ & $\mathrm{X}$ & \\
Dental & $\mathrm{X}$ & $\mathrm{X}$ & \\
Physical Therapy & $\mathrm{X}$ & $\mathrm{X}$ & $\mathrm{X}$ \\
Fitness/Exercise & $\mathrm{X}$ & & \\
Nutrition & $\mathrm{X}$ & & \\
\hline
\end{tabular}

Lighting: Stage lighting allows to create exhilarating visuals that evoke a myriad of emotions, and make the event more remarkable. This requires conventional, intelligent and special stage lighting which needs to be coordinating at a mixing desk with sophisticated computer software and professionals. The stage lighting at these events has very little down time and maintenance of the lights in the hot environment takes on a special challenge. But lighting not only involves stages lighting, but illumination of the various venues including the gathering and sleeping areas. Illumination is also a safety issue and special lighting with its own generators was used at this event, which provided excellent amounts of lumens and task lighting as well. All the venues were very well lit.

Audio: Audio is one of the most important components of the special event, to quote Shakespeare the pen is mightier than the sort and the spoken word is an important factor in disseminating the message to the masses. There were hundreds of loudspeaker systems engaged in the event across the various sites. This required support structures, mostly on scaffolding which was either provided as part of the speaker system as structurally self supporting or by a third party vendor which needed additional coordination of the construction and installation. Some of these towers were also equipped with pullies so that the speakers could be easily lowered. The speakers also had to be protected from the elements mainly rain, either with tarps or water proofed enclosures. The speakers and amplifiers were connected by wire to the mixing console and the microphones, which also engaged wireless microphones and head sets. Audio jamming at these events is an additional issue, especially giving the numerous wireless devices in the area, not to mention about feedback from the mikes to the speakers. The audio was provided by professional companies who had experience with these types of installations. Running wires on the ground and also suspended is always a critical factor especially if they are exposed to the elements over a prolonged period of time.

Video: Audio/Video (AV) go hand in hand, This was a high-tech event with daylight projection (DLP) and large size LED displays which were either supported by tower structures or permanently mounted on trucks as mobile TV screens. Glare was a major issue but these commercial screens were designed for the Thai environmental conditions. The smaller screens also included household TV sets which were provided in the tent cities of the various venues. Plasma screens can be recognized by reflection in the screen and are less suitable for these settings. In addition there were small projection un its which needed to be protected from the elements and required a projection screen. The event provided mostly live video display, which means real-time live streaming video from the various venues, which at times had to be transmitted via satellite from one site to the other. The video also required mobile studios and stationary studios to mix the multiple camera inputs which were obtained by multiple camera crews with stationary and should mounted cameras with wide angle and spot lenses. The stationary cameras also required tower structures with protection from the elements to get shuts from high above along with profession film production equipment and directors.

Satellite Transmission: Satellite connections are crucial for these types of events while most of the TV stations have their own TV truck with satellite uplink, power supply and even mobile air-conditioning units which run of the truck or van mounted generators. The satellite links provide the signals to the various studio facilities as well as between sites. It also allowed down- and up- links in various countries and kept people outside of Thailand informed as well of the on-going events at the various sites. 
Utilities: Another way of looking at logistics is by the general critical infrastructure, which includes, fresh water lines, waste water lines, electrical lines (220V and high voltage lines) as well as audio lines, video lines, telephone lines, computer networks and wireless networks to include wifi and mobile phone access as well as satellite signal up and downlinks. These lines have to be protected from the elements, as well as contact with participants and traffic. The lines occasionally also need to run below ground but often above ground and need to be suspended from a shared structure which requires coordination. There are also right of way issues if these utilities have to be brought to the sight or be generated at the site. The power that could not be brought to the site was generated on-site with various size generators from small footprint Honda generators to large size skip or wheel base mounted diesel generators. There also needed to be electrical panels and breaker systems. The water was provided through existing fire hydrants on-site which often had a distribution head attached with up to 16 lines connecting through blue plastic pipes.

Table 5: Utilities

\begin{tabular}{lllll}
\hline Utilities & $\begin{array}{l}\text { On-Site } \\
\text { Existing }\end{array}$ & Lacking & $\begin{array}{l}\text { Brought to Site } \\
\text { Base Service }\end{array}$ & Additional \\
\hline Electricity & $\mathrm{X}$ & & $\mathrm{X}$ \\
Water & $\mathrm{X}$ & & $\mathrm{X}$ & $\mathrm{X}$ \\
Sewer & & $\mathrm{X}$ & $\mathrm{X}$ & $\mathrm{X}$ \\
Waste Management & & $\mathrm{X}$ & & $\mathrm{X}$ \\
Telephone Services & $\mathrm{X}$ & & $\mathrm{X}$ & $\mathrm{X}$ \\
Wireless Network & $\mathrm{X}$ & $\mathrm{X}$ & $\mathrm{X}$ \\
Satellite Services & & & & $\mathrm{X}$ \\
ATM & $\mathrm{X}$ & & & \\
\hline
\end{tabular}

Staging: Staging is general term of any type of covering either at ground level or evaluated. For an outdoor event floor level covering is required to protect the participants from the elements. As the venue was in an urban area mostly roads have been used, as in for instance in the case of Victory Monument. Frequently the participants purchased for 20 baht aluminum foil that is normally used to manufacture packing material such as potato chip bags. In addition blue and white tarps were frequently used for ground cover if occasionally lawn areas had to be covered as it was the case in Lumpini Park. Raised platform staging is another issue and was used for the event stages. The stages were of various height most of the stages were covered to protect the speakers and entertainers from the elements mostly sunshine. The roof structure and structural support for lighting and sound systems was often supported via winches from columns and could be height adjusted via electrical motors which made installations and modifications of lighting $\mathrm{m}$ ore convenient. Wind loads are a major design consideration when creating staging and covering normal design loads are $70 \mathrm{mph}$. The staging also requires blow thru back scrim, otherwise the wind load will rip the fabric apart. Skirting is applied to the bottom of the stage to obstruct the view and make the stage more appealing. On the top of the stages banners were used with various themes applicable to the topic of the event, there were also posters throughout the venue.

Merchandising: Out of the Thai flag color scheme, a whole line of merchandise developed, from bandanas, T-shirts, baseball caps to polo shirts, ear rings, flag pins and all kind of jewelry in the national colors and the symbol of the movement the whistle which is blown. The development of this merchandise developed through various vendors, without any formal branding. The private sector also takes care of developing and distributing these items at the various venues. Silom road was shut down for weeks and occupied by street vendors which sold various more or less "branded merchandise along with other daily necessity items such as food and mobile phone accessories such as charges, head phones etc. This in itself is a huge investment and logistics effort to deliver these items to the various venues, and to break down the stalls during the night time. Some of the vendors from out of town and down south lived at the site to safeguard their merchandise. These vendor managed inventories followed the regular supply chain management (SCM) principles. Naturally supply chain risk management (SCRM) took on a different meaning in this context of the special event as the supply chain was exposed to additional risks in addition to regular supply chain risks. Demand was difficult to forecast especially with the change in venues and amount of pedestrian traffic.

Discussion: There are valuable lessons to be learned for future outdoor special events. The results already included a discussion of some of the issues to be addressed in the various areas from forecasting 
demand, warehousing to transportation issues. Besides that venue selection, timing, weather, food and beverage, transportation, security and safety, accommodation, personal hygiene, animals, waste management, healthcare, religious services, lighting, audio and visual, satellite services, utilities, staging and merchandising. In addition in special event logistics there is the issue of identity of the event in terms of corporate identity (fonts, colors and logos) which was not an issue here as they were already preexisting. These events also develop their own identity with various expression of art as the event evolves. The logistics issues are exponential as we address the key questions are the location of the event, the duration of the event and the issue of single or multiple locations are being used. The logistics is getting more complex as the number of locations increase and the duration of the event extends. The duration is an important factor concerning resources both material and human resources while time can also be of advantage when it comes to routine tasks as the team is getting used to the supply chain pattern. So the event actually becomes more routine over time and from a supply chain standpoint becomes more institutionalized and takes on the nature of an on-going supply chain. But the challenge is that over time suppliers and participants may change so there is a dynamic element to the event as well as the change of climate over time, as in April the hottest month of Thailand will be entered and the Songkran holiday season provides new momentum and challenges to the logistics of the event. The open ended nature of these types of events makes it touch on long term forecasting of demand and required resources. At the end logistics management is all about managing limited resources most efficient and effectively and the same holds true when it comes to special event logistics. The dynamic nature of these events makes them especially challenging, as nothing remains constant neither space or time, and the event takes on a life of its own past the initial stage which can be pre-planned. Thereby special event logistics is more an art than a science.

\section{Figure 3: Three vectors of Special Events}

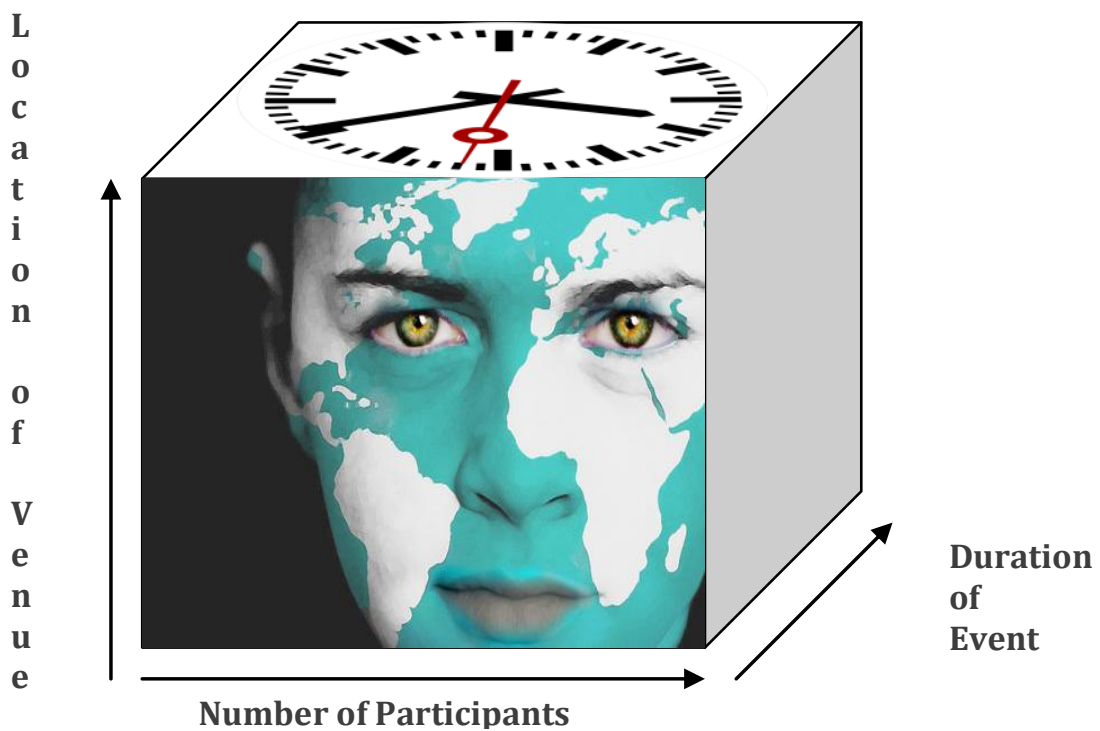

\section{Conclusion}

In conclusion geopolitical events like the "Bangkok Shutdown 2014" have special logistics requirements which go beyond the normal supply chain management (SCM). There is nothing regular about these events and demand forecasting is difficult to do beyond the early days of the event. Multiple venues are certainly a greater challenge than a single large event where economy of scale kicks in and outweigh the larger number of participants. Multiple sites need exponentially more staff to manage and operate the activities. Outdoor concerts in a way have a lot in common with outdoor geopolitical events, the key word is outdoor (Tum, Norton \& Wright, 2006).

The lessons to be learned can be summarized in supplies needed per participants (food \& beverages, medicine) as well as resources based on number of participants (transportation, shelter, AV, phone services, electricity consumption, toilets, showers). The timing and venue selection are the two key base decisions. The velocity of special events has increased over the years and they are real time in every meaning of the word. Multimedia and on-line coverage has also changed the events and the expectations in addition as a new phenomena automated teller machines (ATM) as well as mobile phone connectivity 
have to be brought to the venue. There are lessons to be learned from history and past geopolitical events. To get a even better understanding of the phenomena of the special event logistics surrounding these political events with large number of volunteers and participants, a comparative study of invents in the same country and geographic region would be more helpful than comparing similar events in other parts of the world, as the dynamics and velocity of the activities are quite different. The Bangkok Shut Down has not ended when this paper was written it therefore would be interesting to conduct a follow up study of the event after it was completed so that the formal lessons learned can be documented in retrospect and in a follow-up study comparisons can be made finding out the similarities and dissimilarities of these types of events and how they evolved over time from a logistics standpoint, in order to create special event logistics theory from a grounded theory approach (Whetten, 1989).

\section{Figure 4: Special Event Logistics Issues}

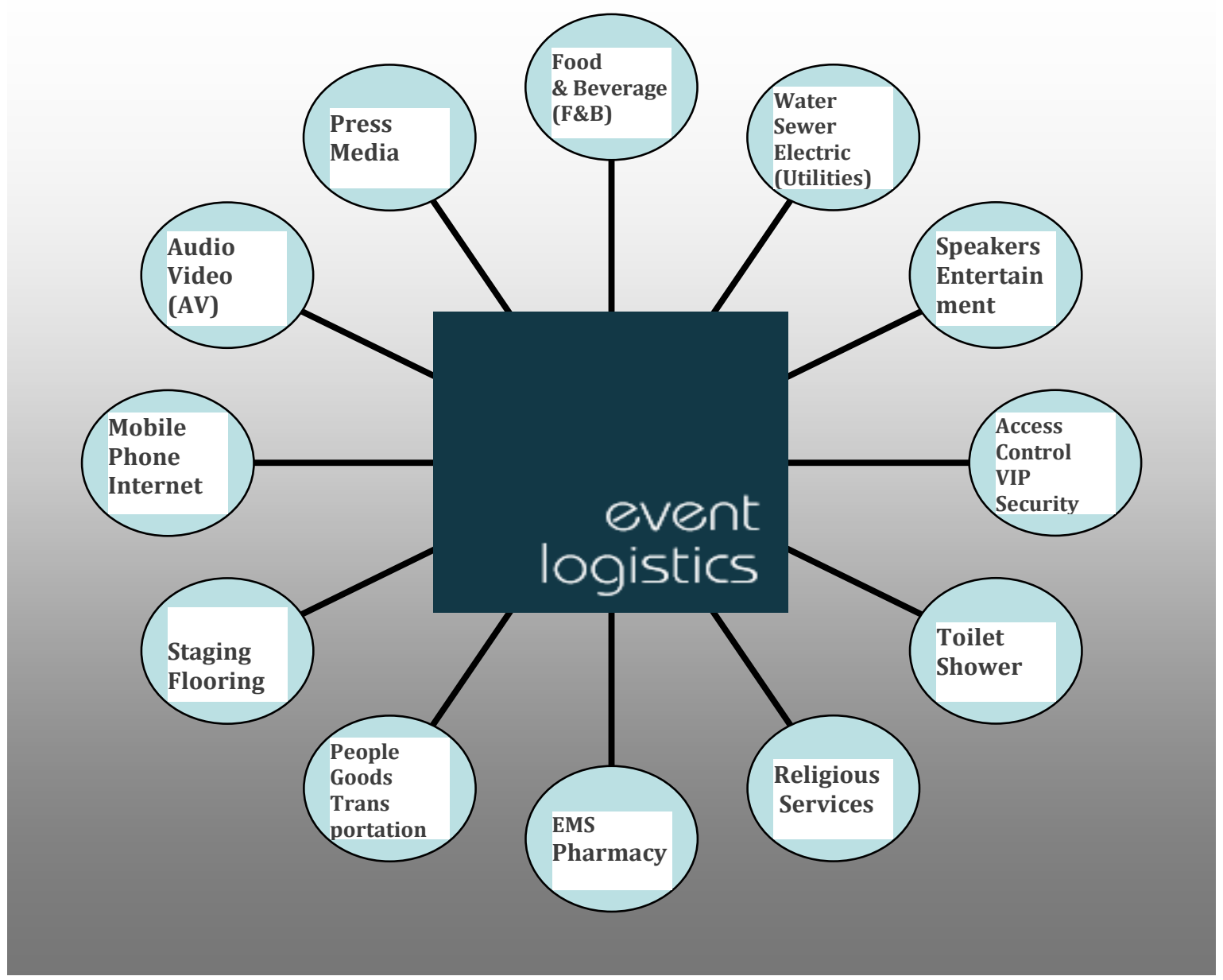

\section{References}

Armstrong, J. S. (2001). Planning Special Events. New York: Josse Bass Wiley.

Bell, C. (1969). A Note on Participant Observation. Sociology, 3(3), 417-418.

Boehme, A. J. (1999). Planning Successful Meetings and Events. New York: AMACOM.

Chenoweth, E. \& Orion, A. L. (2013). Unpacking nonviolent campaigns: Introducing the NAVCO 2.0 dataset. Journal of Peace Research, 50(3), 415-423.

Chenoweth, E. \& Orion, A. L. (2013). Nonviolent and Violent Campaigns and Outcomes (NAVCO) Data Project Campaign-Year Data Codebook. (May): 1-19.

Health and Safety Executive. (1999). The Event Safety Guide. London: HSE

Glaser, B. G. \& Strauss, A. L. (1967). The Discovery of Grounded Theory: Strategies for Qualitative Research, Chicago, Aldine Publishing Company

Maslow, A. H. (1970). Motivation and Personality (2nd ed.). New York: Harper and Row. 
McCurley, S. (2002). Volunteer Management Bibliography. Philadelphia: Energize, Inc. Nichols, D. (2003). Examples of Excellence. The Meeting Professionals, 23(10).

Robbe, D. (2000). Expositions and Trade Shows. Canada: Wiley.

Tarlow, P. (2002). Event Risk Management and Safety. New York: Wiley.

Tum, J., Norton, P. \& Wright, N. J. (2006). Management of Event Operations. Oxford: Elsevier

Whetten, D. A. (1989). What Constitutes a Theoretical Contribution? Academy of Management Review, 14(4), 1989, 490-495. 